Article

\title{
Analysis of an Air Powered Engine System Using a Multi-Stage Radial Turbine
}

\author{
Xuehui Zhang ${ }^{1,2}$, Haisheng Chen ${ }^{1, *}$, Xiaohui Yan ${ }^{1}$, Xinjing Zhang ${ }^{1}$ and Chunqing Tan ${ }^{1}$ \\ 1 Institute of Engineering Thermophysics, Chinese Academy of Sciences, 11 Beisihuanxi Road, \\ Beijing 100190, China; E-Mails: zhangxuehui@mail.etp.ac.cn (X.Z.); \\ yanxiaohui5123@yahoo.com.cn (X.Y.); zhangxinjing@iet.cn (X.Z.); tan@mail.etp.ac.cn (C.T.) \\ 2 University of Chinese Academy of Sciences, 19A Yuquan Road, Beijing 100049, China \\ * Author to whom correspondence should be addressed; E-Mail: chen_hs@mail.etp.ac.cn; \\ Tel.: +86-10-82543148; Fax: +86-10-82543079.
}

Received: 14 January 2013; in revised form: 21 March 2013 / Accepted: 25 March 2013 /

Published: 28 March 2013

\begin{abstract}
The performance and design criteria of air powered multistage turbines are studied thermodynamically in this paper. In-house code is developed in the $\mathrm{C}++$ environment and the characteristics of four-stage turbines with inter-heating are analyzed in terms of maximum thermal efficiency, maximum exergy efficiency and maximum work output over the inlet temperature range of $293 \mathrm{~K}-793 \mathrm{~K}$ with inlet pressure of $70 \mathrm{bar}$. It is found that the maximum thermal efficiency, maximum exergy efficiency and maximum work output are $62.6 \%, 91.9 \%, 763.2 \mathrm{~kJ} / \mathrm{s}$, respectively. However, the thermal efficiency, exergy efficiency and work output are not equivalent for the four-stage radial turbine. It is suggested that at low working temperatures both maximum exergy efficiency and maximum work output can be used as the design objective, however, only maximum work output can be used as the design objective for the four-stage radial turbine over the working temperature range in this work.
\end{abstract}

Keywords: thermodynamic analysis; radial turbine; thermal efficiency; exergy efficiency; work output 


\section{Nomenclature:}

$\operatorname{Ex}_{(\mathrm{n}-1)^{\prime}-\mathrm{n}}$ The variation of exergy during the heating process $(\mathrm{n}-1)^{\prime}-\mathrm{n}, \mathrm{kJ} / \mathrm{s}$

$\mathrm{Ex}_{\mathrm{s}} \quad$ The variation of exergy during the heating process of a single stage radial turbine, $\mathrm{kJ} / \mathrm{s}$

$\mathrm{Ex}_{\text {tot }} \quad$ Total exergy input of the system, $\mathrm{kJ} / \mathrm{s}$

$\mathrm{h} \quad$ Specific enthalpy, $\mathrm{kJ} / \mathrm{kg}$

$\mathrm{h}_{\mathrm{id}} \quad$ Ideal specific enthalpy, $\mathrm{kJ} / \mathrm{kg}$

$\mathrm{H} \quad$ Enthalpy, $\mathrm{kJ} / \mathrm{s}$

$\mathrm{m} \quad$ Mass flow, $\mathrm{kg} / \mathrm{s}$

$\mathrm{P} \quad$ Pressure, bar

$\mathrm{Q}_{(\mathrm{n}-1)^{\prime}-\mathrm{n}}$ Heat absorbed during the heating process $(\mathrm{n}-1)^{\prime}-\mathrm{n}, \mathrm{kJ} / \mathrm{s}$

$\mathrm{Q}_{\mathrm{s}} \quad$ Heat absorbed during the heating process of a single stage radial turbine, $\mathrm{kJ} / \mathrm{s}$

s $\quad$ Entropy, $\mathrm{kJ} /(\mathrm{kg})(\mathrm{K})$

T Temperature, $\mathrm{K}$

$\mathrm{T}_{6} \quad$ External heat source temperature, $\mathrm{K}$

w Specific work, $\mathrm{kJ} / \mathrm{kg}$

W Total work output of the turbine, $\mathrm{kJ} / \mathrm{s}$

$\mathrm{W}_{\mathrm{ac}, \mathrm{n}-\mathrm{n}}$ Actual Work output during the expansion process $\mathrm{n}-\mathrm{n}^{\prime}, \mathrm{kJ} / \mathrm{s}$

$\mathrm{W}_{\mathrm{id}, \mathrm{n}-\mathrm{n}^{\prime}}$ Ideal Work output during the expansion process $n-\mathrm{n}^{\prime}, \mathrm{kJ} / \mathrm{s}$

$\eta_{n-n^{\prime}} \quad$ Isentropic efficiency during the expansion process $n-n^{\prime}$

$\eta_{\mathrm{ex}} \quad$ Exergy efficiency

$\eta_{\text {th }} \quad$ Thermal efficiency

$\pi_{\mathrm{n}} \quad$ Expansion ratio of the $\mathrm{nth}$ stage

\section{Subscripts}

$0 \quad$ Ambient state

$0^{\prime} \quad$ The state of air entering the system

1 The state of air entering the first stage radial turbine

1' The state of air leaving the first stage radial turbine

2 The state of air entering the second stage radial turbine

2' The state of air leaving the second stage radial turbine

3 The state of air entering the third stage radial turbine

3' The state of air leaving the third stage radial turbine

4 The state of air entering the fourth stage radial turbine

4' The state of air leaving the fourth stage radial turbine

\section{Introduction}

Radial turbines have been widely used for small scale gas turbines, cryogenic expanders and automotive turbochargers because of their simplicity, low cost, relatively high performance and good installation features [1]. Over the past decades, extensive investigations have been made into single-stage radial turbines, including design methodology, thermodynamic analysis, internal flow and heat transfer, 
and optimization [2-6]. However, there is a lack of literature on multi-stage radial turbines. With total expansion ratio increasing, multistage radial turbines are urgently needed for waste heat and pressure recovery, solar thermal power and compressed air energy storage [7-10]. Clearly, there is a need to investigate the multistage radial turbine in order to achieve both high expansion ratios and high performance. Although internal flow and heat transfer in single stage and multistage radial turbines are similar, the stage matching and design criteria of the multistage radial turbine are more complex. This paper aims to study the design criteria for the multistage turbine and the fundamental of designing of an engine with a multistage turbine. A four-stage radial turbine with inter-heating will be analyzed thermodynamically by using the methodology based on both the first and second laws of thermodynamics, and the thermal efficiency, exergy efficiency and work output will be discussed in detail for a better understanding of the stage matching and design criteria.

\section{Description of the System}

The four-stage radial turbine system with inter-heating is shown schematically in Figure 1. This kind of turbine has great potential for compressed air energy storage systems [10,11], air fueled car engines [12-14] and organic Rankine cycles [7]. During operation, compressed air is heated by heat exchanger 1 via an external heat source, and then expands in the first stage of the radial turbine to produce work. The temperature and pressure of the working air at the first stage outlet will decrease due to the enthalpy drop associated with the expansion process. The compressed air is then reheated through heat exchanger 2 and expands in the second stage. Similarly, the compressed air passes through the third and fourth stages of the turbine, and finally exhausts into the ambience. The following conditions are considered in the following analyses:

Mass flow: $\mathrm{m}=1 \mathrm{~kg} / \mathrm{s}$.

Ambient temperature: $\mathrm{T}_{0}=293 \mathrm{~K}$

External heat source temperature: $\mathrm{T}_{6}=293 \mathrm{~K}$ to $793 \mathrm{~K}$

Ambient pressure: $\mathrm{P}_{0}=1$ bar

Inlet pressure: $\mathrm{P}_{0^{\prime}}=70$ bar

Figure 1. Schematic diagram of the four-stage radial turbine system.

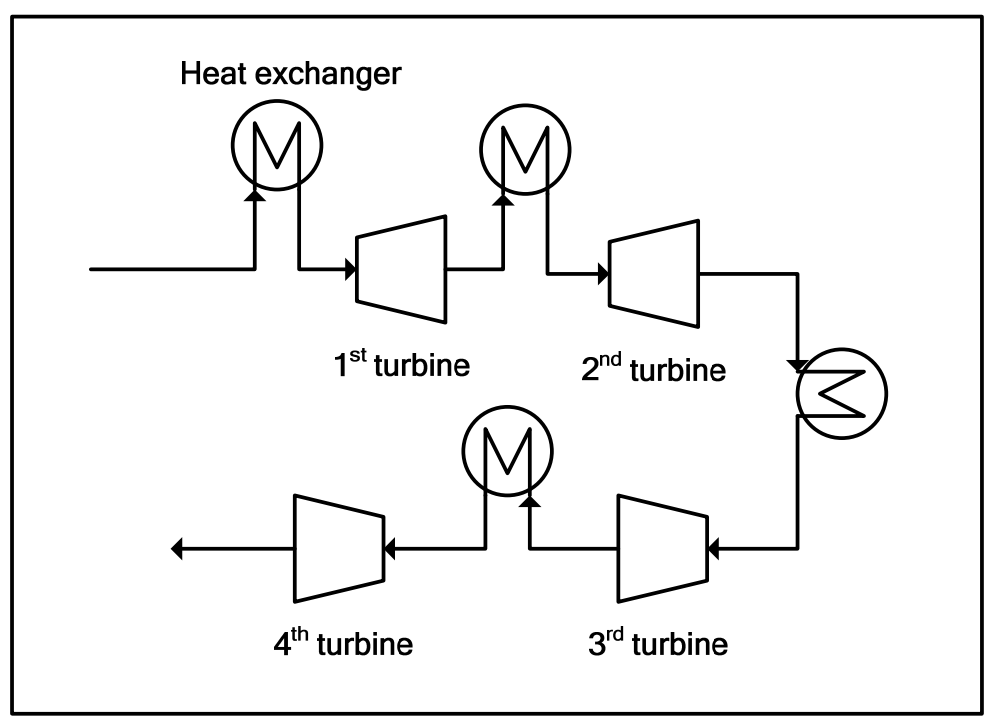


The reasons to consider 70 bar as the inlet pressure and $293 \mathrm{~K}$ to $793 \mathrm{~K}$ as the inlet temperature are as follows: (i) they are technically feasible for a four-stage radial turbine [11-14]; (ii) the high pressure limit of compact heat exchanger is now about 70 bar [15]; and (iii) the waste heat temperature in industry is below $500{ }^{\circ} \mathrm{C}(793 \mathrm{~K})$ [15]. On the other hand, for a turbine with an expansion ratio of 70 , three to five stages are reasonable $[14,16]$. At the same time, a back-to-back structure is normally applied for the multistage radial turbines $[17,18]$. This is why an even stage number (four) is used for the turbine. Theoretically, the results for three, four and five stages are similar.

\section{Analysis Methodology}

\subsection{Thermodynamic Analyses}

Figure 2 shows a typical theoretical working process of the four-stage radial turbine in the temperature-entropy plane ( $T-S$ diagram). It consists of four heating processes 0 ' $-1,1$ ' $-2,2$ ' -3 and 3'-4 in which the compressed air is heated isobarically and four expansion processes 1-1', 2-2', 3-3' and 4-4' in which the compressed air expands to produce work. Point 0' refers to the state of the compressed air entering the system and the pressure of state 4' equals the ambient pressure. The following figure shows a detailed analysis of these processes.

Figure 2. $T-S$ diagram of the four-stage radial turbine.

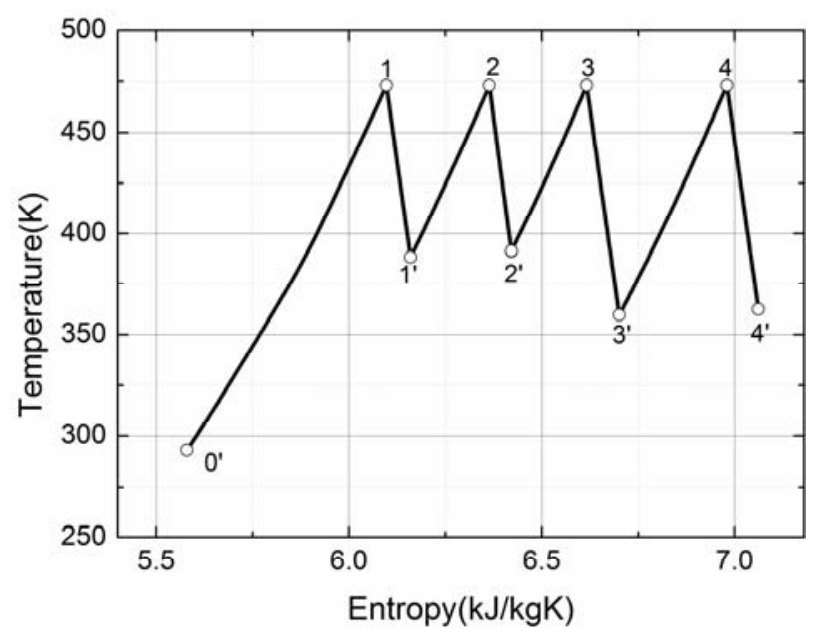

The enthalpy $\mathrm{H}_{\mathrm{n}}$ of the compressed air (State $\mathrm{n}$ ) is given as:

$$
\mathrm{H}_{\mathrm{n}}=\mathrm{m}_{\mathrm{n}} \mathrm{h}_{\mathrm{n}}
$$

where $\mathrm{m}$ and $\mathrm{h}$ represent mass flow and specific enthalpy, and subscript represents the state point in Figure 2. Specific enthalpy $h_{n}$ is a function of pressure $P_{n}$ and temperature $T_{n}$. The exergy of the compressed air (State $n$ ) is given by:

$$
\mathrm{Ex}_{\mathrm{n}}=\mathrm{m}_{\mathrm{n}}\left[\left(\mathrm{h}_{\mathrm{n}}-\mathrm{h}_{0}\right)-\mathrm{T}_{0}\left(\mathrm{~s}_{\mathrm{n}}-\mathrm{s}_{0}\right)\right]
$$

where T, Ex and s represent temperature, exergy and entropy, respectively, and the subscript 0 represents the ambient state. The heat and exergy absorbed during the heating process (Process $\left.(n-1)^{\prime}-n\right)$ by the compressed air are given respectively as: 


$$
\begin{gathered}
\mathrm{Q}_{(\mathrm{n}-1)^{\prime}-\mathrm{n}}=\mathrm{H}_{\mathrm{n}}-\mathrm{H}_{(\mathrm{n}-1)^{\prime}} \\
\mathrm{Ex}_{(\mathrm{n}-1)^{\prime}-\mathrm{n}}=\mathrm{Ex}_{\mathrm{n}}-\mathrm{Ex}_{(\mathrm{n}-1)^{\prime}}
\end{gathered}
$$

The expansion process (Process $n-n^{\prime}$ ) can be characterized by the parameter isentropic efficiency, $\eta_{n-n^{\prime}}$, defined as the ratio of the actual work $\left(W_{a c, n-n^{\prime}}\right)$ to the ideal isentropic work $\left(W_{i d, n-n^{\prime}}\right)$ :

$$
\eta_{\mathrm{n}-\mathrm{n}^{\prime}}=\frac{\mathrm{W}_{\mathrm{ac}, \mathrm{n}-\mathrm{n}^{\prime}}}{\mathrm{W}_{\mathrm{id}, \mathrm{n}-\mathrm{n}^{\prime}}}
$$

The actual work output $\mathrm{W}_{\mathrm{ac}, \mathrm{n}-\mathrm{n}^{\prime}}$ of the expansion process (Process $\mathrm{n}-\mathrm{n}^{\prime}$ ) is therefore given by:

$$
\mathrm{W}_{\mathrm{ac}, \mathrm{n}-\mathrm{n}^{\prime}}=\mathrm{H}_{\mathrm{n}}-\mathrm{H}_{\mathrm{n}^{\prime}}=\eta_{\mathrm{n}-\mathrm{n}^{\prime}}, \mathrm{W}_{\mathrm{id}, \mathrm{n}-\mathrm{n}^{\prime}}=\eta_{\mathrm{n}-\mathrm{n}^{\prime}}\left(\mathrm{m}_{\mathrm{n}} \mathrm{h}_{\mathrm{n}}-\mathrm{m}_{\mathrm{n}}, \mathrm{h}_{\mathrm{id}, \mathrm{n}^{\prime}}\right)
$$

where $h_{\text {id,n' }}$ is a function of entropy $s_{n}$ and pressure $P_{n^{\prime}}$, and the pressure $P_{n^{\prime}}$ is given as:

$$
P_{n^{\prime}}=\frac{P_{n}}{\pi_{n}}
$$

where $\pi_{\mathrm{n}}$ is the expansion ratio of the $n$th stage radial turbine and satisfies the equation:

$$
\prod_{\mathrm{n}=1}^{4} \pi_{\mathrm{n}}=\mathrm{P}_{0^{\prime}} / \mathrm{P}_{4^{\prime}}
$$

The expansion ratio limit of single radial turbine is now about 10-15 [19], the expansion ratio limit is given by the inequality:

$$
1 \leq \pi_{\mathrm{n}} \leq 15
$$

\subsection{Evaluation Criteria}

Assuming that $\mathrm{H}_{0^{\prime}}, \mathrm{Ex}_{0^{\prime}}$ are the enthalpy and exergy at the entry of a single stage radial turbine with heating system, $\mathrm{Q}_{\mathrm{s}}$ and $\mathrm{Ex}_{\mathrm{s}}$ are the heat and exergy absorbed during the heating process, $\mathrm{W}$ is the work output of the radial turbine, the thermal efficiency $\left(\eta_{\mathrm{th}}\right)$ and exergy efficiency $\left(\eta_{\mathrm{ex}}\right)$ of the single radial turbine can be given as:

$$
\begin{gathered}
\eta_{\text {th }}=\frac{W}{H_{0^{\prime}}+Q_{s}} \\
\eta_{\text {ex }}=\frac{W}{E_{0_{0^{\prime}}}+E_{s}}
\end{gathered}
$$

where $\mathrm{H}_{0^{\prime}}, \mathrm{Q}_{\mathrm{s}}, \mathrm{Ex}_{0^{\prime}}$ and $\mathrm{Ex}_{\mathrm{s}}$ are constant at a given working condition. As a result, thermal efficiency, exergy efficiency and power output are equivalent for single stage radial turbine, that is to say, maximum thermal efficiency means maximum exergy efficiency and maximum power output for single stage radial turbine, so any of them can be considered as the criterion for evaluating a single stage radial turbine's performance. In other words, given the working conditions, a good design of a single stage radial turbine with or without a heating system will have a high thermal efficiency, a high exergy efficiency and a large power output, but in multistage radial turbine, the heat and exergy absorbed during the heating process are not constant at a given working condition and they are 
influenced by expansion ratio of each stage, so theoretical thermodynamic analysis is conducted as follows to answer if this is also applicable for evaluating multistage radial turbines with inter-heating.

The energy distribution of the four-stage radial turbine is shown in Figure 3. For an open thermodynamic system like the radial turbine, the energy input consists of the enthalpy of the compressed air at the entry $\mathrm{H}_{0}$, and the heat absorbed during four heating processes $\left(\mathrm{Q}_{0^{\prime}-1}, \mathrm{Q}_{1^{\prime}-2}, \mathrm{Q}_{2^{\prime}-3}\right.$ and $\left.\mathrm{Q}_{3^{\prime}-4}\right)$. The energy output of the system is the work output of four radial turbines $\left(\mathrm{W}_{\mathrm{ac}, 1-1}, \mathrm{~W}_{\mathrm{ac}, 2-2^{\prime}}\right.$, $\mathrm{W}_{\mathrm{ac}, 3^{-3} 3^{\prime}}$ and $\mathrm{W}_{\mathrm{ac}, 4^{\prime} 4^{\prime}}$ ) and the enthalpy of the compressed air at the outlet $\mathrm{H}_{4^{\prime}}$. Therefore the power output and thermal efficiency of the four-stage radial turbine can be expressed as:

$$
\begin{gathered}
\mathrm{W}=\sum_{\mathrm{n}=1}^{4} \mathrm{~W}_{\mathrm{ac}, \mathrm{n}-\mathrm{n}^{\prime}} \\
\eta_{\mathrm{th}}=\frac{\sum_{\mathrm{n}=1}^{4} \mathrm{~W}_{\mathrm{ac}, \mathrm{n}-\mathrm{n}^{\prime}}}{\mathrm{H}_{0^{\prime}}+\sum_{\mathrm{n}=1}^{4} \mathrm{Q}_{(\mathrm{n}-1)^{\prime}-\mathrm{n}}}
\end{gathered}
$$

Figure 3. Energy distribution of the four-stage radial turbine.

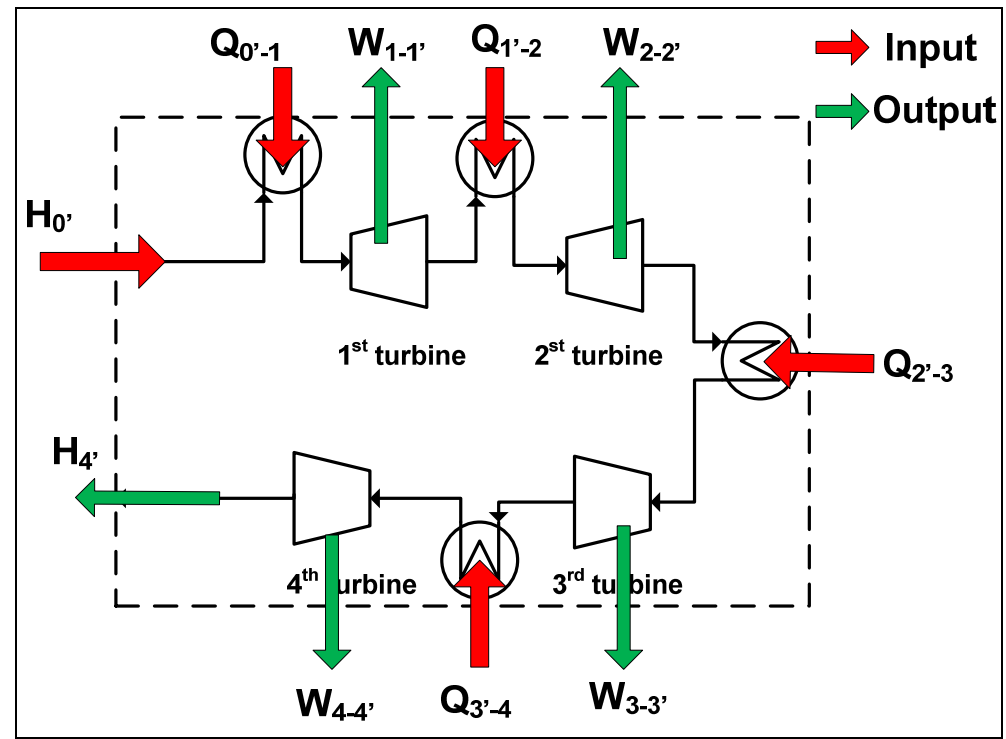

Exergy represents the available work of working fluid, the greater the value of exergy is, the more work a working fluid can generate. Two typical exergy distributions of the four-stage radial turbine are shown in Figure 4a,b. The red arrows and green arrows, represent the exergy input and output of the system, respectively. In the first case (Figure 4a), the value of exergy $\operatorname{Ex}_{n}$ at State $n$ after heating is greater than that of exergy $\operatorname{Ex}_{(n-1)}$ at State $n-1$ ' before heating, the compressed air absorbs the heat during the heating processes and the heating processes increases the exergy of the compressed air. The exergy input is the sum of the exergy of the compressed air at the entry and the exergy absorbed during the heating processes, so the exergy efficiency of the four-stage radial turbine is defined as:

$$
\eta_{\mathrm{ex}}=\frac{\sum_{\mathrm{n}=1}^{4} \mathrm{~W}_{\mathrm{ac}, \mathrm{n}^{-n^{\prime}}}}{\mathrm{Ex}_{0^{\prime}}+\sum_{\mathrm{n}=1}^{4} \mathrm{Ex}_{(\mathrm{n}-1)^{\prime}-\mathrm{n}}}
$$


Figure 4. Exergy distribution of the four-stage radial turbine.

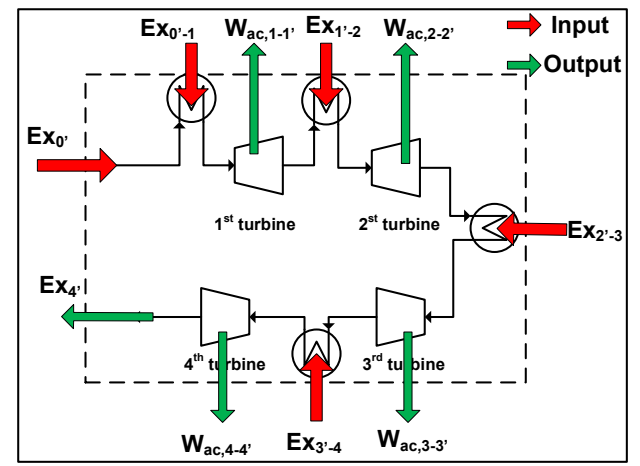

(a)

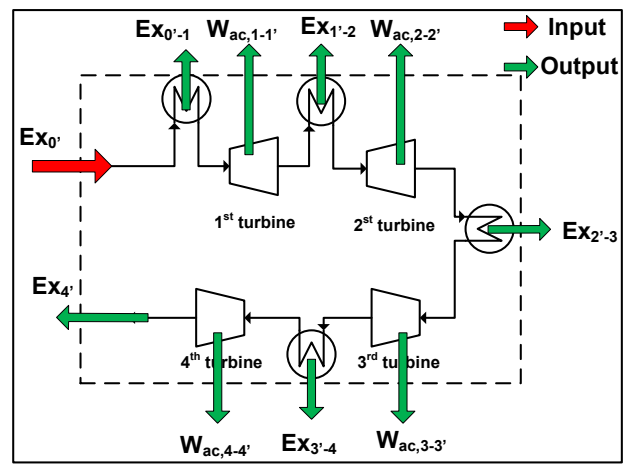

(b)

In some cases, the temperature of external heat source is close to ambient temperature and the temperature of the compressed air before heating is lower than ambient temperature, so that the value of exergy $\operatorname{Ex}_{(\mathrm{n}-1)}$ ' before heating is greater than that of exergy $\mathrm{Ex}_{\mathrm{n}}$ after heating as in Figure $4 \mathrm{~b}$. In this case, the exergy of the compressed air decreases though it absorbs the heat during the heating processes. In other words, the compressed air gets the energy but losses the ability to generate available work. Figure $4 \mathrm{~b}$ shows the case in which the temperature before heating $\left(\mathrm{T}_{0^{\prime}}, \mathrm{T}_{1}, \mathrm{~T}_{2}\right.$, and $\left.\mathrm{T}_{3}{ }^{\prime}\right)$ is lower than ambient temperature. In this case, $\mathrm{Ex}_{0^{\prime}-1}, \mathrm{Ex}_{1^{\prime}-2}, \mathrm{Ex}_{2^{\prime}-3}$ and $\mathrm{Ex}_{3^{\prime}-4}$ are negative which implies that $\mathrm{Ex}_{0^{\prime}-1}, \mathrm{Ex}_{1^{\prime}-2}, \mathrm{Ex}_{2^{\prime}-3}$ and $\mathrm{Ex}_{3^{\prime}-4}$ are exergy output of the system. Its exergy input is only the exergy of the compressed air at the entry $\left(\mathrm{Ex}_{0}{ }^{\prime}\right)$. On the other hand, the effective output does not change, i.e., $\left(\mathrm{W}_{\mathrm{ac}, 1-1},+\mathrm{W}_{\mathrm{ac}, 2-2},+\mathrm{W}_{\mathrm{ac}, 3-3^{3}}+\mathrm{W}_{\mathrm{ac}, 4-4^{4}}\right)$. Therefore, the definition of exergy efficiency can be expressed as:

$$
\eta_{\mathrm{ex}}=\frac{\sum_{\mathrm{n}=1}^{4} \mathrm{~W}_{\mathrm{ac}, \mathrm{n}-\mathrm{n}^{\prime}}}{\mathrm{Ex}_{0^{\prime}}}
$$

Under actual working conditions, the exergy before heating is greater than that after heating in some heating processes, this is contrary in other heating processes, this is to say, some heating processes get exergy, others loss exergy, so exergy input of the system can be given as:

$$
\mathrm{Ex}_{\text {tot }}=\mathrm{Ex}_{0^{\prime}}+\sum_{\mathrm{n}=1}^{4} \mathrm{Ex}_{(\mathrm{n}-1)^{\prime}-\mathrm{n}} \mathrm{H}\left(\mathrm{Ex}_{(\mathrm{n}-1)^{\prime}-\mathrm{n}}\right)
$$

$\mathrm{H}(\mathrm{x})$ is Heaviside step function, which is defined as: 


$$
H(x)= \begin{cases}0, & x<0 \\ 1, & x \geq 0\end{cases}
$$

The exergy efficiency of the four-stage radial turbine is then defined as:

$$
\eta_{\mathrm{ex}}=\frac{\sum_{\mathrm{n}=1}^{4} \mathrm{~W}_{\mathrm{ac}, \mathrm{n}-\mathrm{n}^{\prime}}}{\mathrm{Ex}_{\mathrm{tot}}}
$$

\subsection{Numerical Methodology}

An in-house code is developed based on the $\mathrm{C}++$ environment and the physical properties of the air are obtained from the REFPROP database. The flow chart of the code is shown in Figure 5. For a given stage efficiency and a given external heat source temperature, the thermal efficiency, exergy efficiency and power output at different expansion ratios are calculated and stored in an array. During the calculations, constrains of expansion ratio for each stage are imposed. After the calculation, the performance of the turbine at maximum thermal efficiency, maximum exergy efficiency and maximum power output can be obtained by comparing the data in the array.

Figure 5. Flow chart of in-house code.

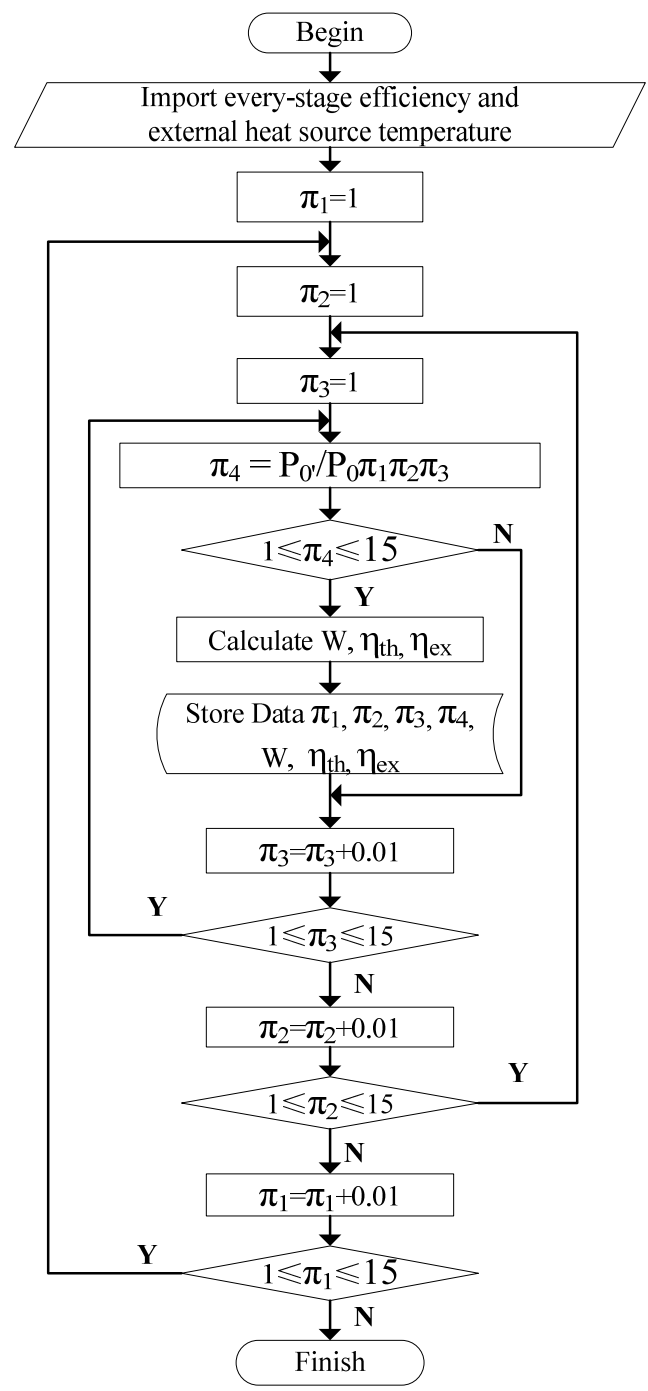




\section{Results and Discussion}

\subsection{Maximum Thermal Efficiency}

The efficiency of radial turbine is influenced by many factors such as working condition, structure, loading coefficient, flow coefficient and so on [1,20-21]. As a thermodynamic analysis, in general, the detailed design of the turbine has not yet conducted and detailed parameters of the turbine are not available yet. A practical way is to consider a range of such parameters and the trends of stage performance characteristic are obtained over the range [21]. The range considered should cover the practical value of the parameters. Three efficiencies, $70 \%, 80 \%$ and $90 \%$, of the turbine are considered in the calculations. The range (70\%-90\%) covers those of most turbines [1-2,4,20-22].

As shown in Equation (13), the definition of thermal efficiency is based on the first law of thermodynamics, which refers to the system's ratio of energy output to energy input. The expansion ratios of four stages and characteristics corresponding to maximum thermal efficiency are shown in Figures 6 and 7, respectively.

In Figure 6, the expansion ratios of four stages corresponding to the maximum thermal efficiency are plotted as a function of working temperature. It can be seen that the expansion ratios of four stages nearly keep constant for the working temperature, and that of the fourth stage is much higher than those of the first three stages. To illustrate the mechanism behind this, the definition of the thermal efficiency (Equation 13) can be expressed as following equation.

$$
\begin{aligned}
\eta_{\text {th }}= & \frac{\sum_{n=1}^{4} \mathrm{~W}_{\mathrm{ac}, \mathrm{n}-\mathrm{n}^{\prime}}}{\mathrm{H}_{0^{\prime}}+\sum_{\mathrm{n}=1}^{4} \mathrm{Q}_{(\mathrm{n}-1)^{\prime}-\mathrm{n}}} \\
= & \frac{\mathrm{W}_{1-1^{\prime}}+\mathrm{W}_{2-2^{\prime}}+\mathrm{W}_{3-3^{\prime}}+\mathrm{W}_{4-4^{\prime}}+\mathrm{H}_{4^{\prime}}-\mathrm{H}_{4^{\prime}}}{\mathrm{H}_{0^{\prime}}+\mathrm{Q}_{0^{\prime}-1}+\mathrm{Q}_{1^{\prime}-2}+\mathrm{Q}_{2^{\prime}-3}+\mathrm{Q}_{3^{\prime}-4}} \\
= & \frac{\mathrm{W}_{1-1^{\prime}}+\mathrm{W}_{2-2^{\prime}}+\mathrm{W}_{3-3^{\prime}}+\mathrm{W}_{4-4^{\prime}}+\mathrm{H}_{4^{\prime}}}{\mathrm{h}_{0^{\prime}}+\mathrm{Q}_{0^{\prime}-1}+\mathrm{Q}_{1^{\prime}-2}+\mathrm{Q}_{2^{\prime}-3}+\mathrm{Q}_{3^{\prime}-4}}-\frac{\mathrm{H}_{4^{\prime}}}{\mathrm{h}_{0^{\prime}}+\mathrm{Q}_{0^{\prime}-1}+\mathrm{Q}_{1^{\prime}-2}+\mathrm{Q}_{2^{\prime}-3}+\mathrm{Q}_{3^{\prime}-4}} \\
= & 1-\frac{\mathrm{H}_{4^{\prime}}}{\mathrm{H}_{0^{\prime}}+\sum_{\mathrm{n}=1}^{4} \mathrm{Q}_{(\mathrm{n}-1)^{\prime}-\mathrm{n}}}
\end{aligned}
$$

It can be seen that the larger expansion ratio of the fourth stage can decrease the energy leaving the system $\left(\mathrm{H}_{4}\right)$, hence increasing the total thermal efficiency. This is why the expansion ratios of the fourth stage at efficiencies investigated $(70 \%, 80 \%$ and $90 \%)$ all reach the expansion ratio limit. From Equation (19) it can be derived that there are two ways to increase the thermal efficiency of the four-stage radial turbine, one is decreasing the energy leaving the system $\left(\mathrm{H}_{4}\right)$, the other is increasing the energy entering the system $\left(\mathrm{H}_{0^{\prime}}, \mathrm{Q}_{0^{\prime}-1}, \mathrm{Q}_{1^{\prime}-2}, \mathrm{Q}_{2^{\prime}-3}\right.$ and $\left.\mathrm{Q}_{3^{\prime}-4}\right)$. The energy entering the system $\mathrm{H}_{0^{\prime}}$ and the heat absorbed during the first heating process $\mathrm{Q}_{0^{\prime}-1}$ are given by the working condition of the turbine, the others $\left(\mathrm{Q}_{1^{\prime}-2}, \mathrm{Q}_{2^{\prime}-3}\right.$ and $\left.\mathrm{Q}_{3^{\prime}-4}\right)$ depend on the work output of the first three stages. The more the work output of the first three stages, the more the energy entering the system, that is to say, to maximize the energy input is to maximize the work output. If the working fluid is perfect gas, the expansion ratios of the first three stages should be identical to maximize the work output. The expansion ratio increases 
from the first stage to the third stage because of the properties of real air, i.e., the enthalpy drop is influenced by working pressure.

Figure 6. Expansion ratio as a function of temperature.

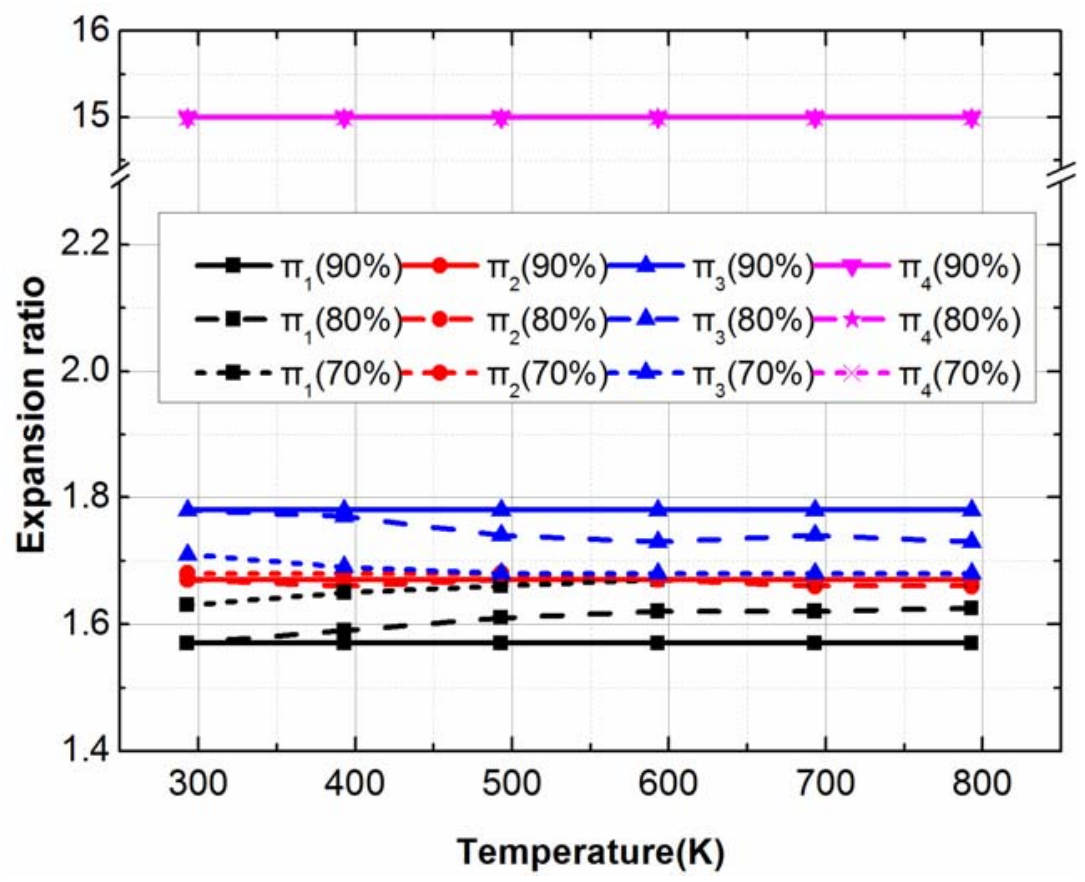

Figure 7. Characteristics corresponding to maximum thermal efficiency.

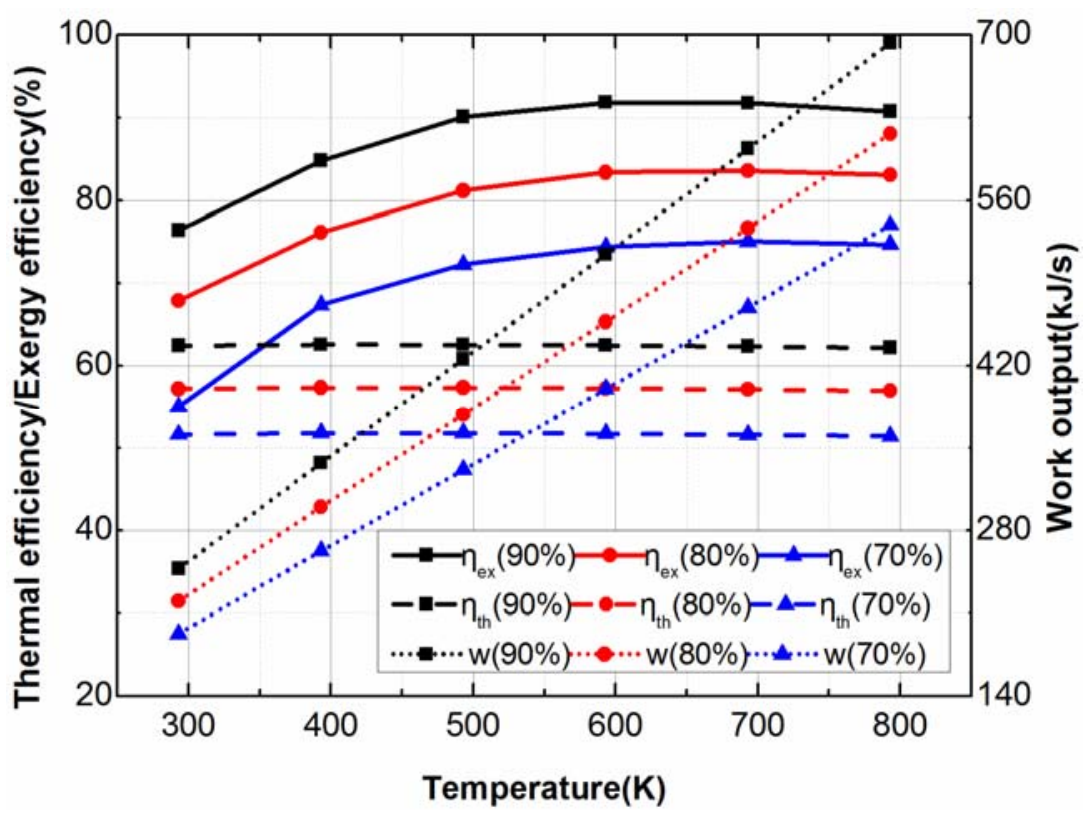

Work output, thermal efficiency and exergy efficiency corresponding to maximum thermal efficiency are shown in Figure 7. The work output increases almost linearly with increasing temperature under maximum thermal efficiency, this is because the inlet temperature increases, the enthalpy drop through expansion process will increase. One can see that work output increases from $192.6 \mathrm{~kJ} / \mathrm{s}$ to $247.5 \mathrm{~kJ} / \mathrm{s}$ at $293 \mathrm{~K}$ and increases from $539.3 \mathrm{~kJ} / \mathrm{s}$ to $693.3 \mathrm{~kJ} / \mathrm{s}$ at $793 \mathrm{~K}$ when the stage efficiency increases from $70 \%$ to $90 \%$, work output is strongly influenced by stage efficiency. When 
the state parameters of air at the entry and expansion ratio are given, the ideal work output can be derived, so work output is directly proportional to stage efficiency according to Equation (5).

In Figure 7, by increasing working temperature from $293 \mathrm{~K}$ to $793 \mathrm{~K}$, the maximum thermal efficiency firstly increases and then decreases, but the difference between the maximum and the minimum values is small $(<0.5 \%)$. The energy leaving the system $\left(\mathrm{H}_{4}\right)$ increases with working temperature, then but the energy input also increases, their growth rates are nearly same, so the thermal efficiency is almost identical at the temperature investigated $(293 \mathrm{~K}-793 \mathrm{~K})$. It can also be seen, in Figure 7, the maximum thermal efficiency increases with increasing turbine efficiency.

It can be seen from Figure 7 that the exergy efficiency increases with increasing working temperature at a given stage efficiency and the increasing rates at low working temperatures are much higher than those at high working temperatures. The reason is that the temperature in the outlet of the fourth stage increases as the working temperature increases, so that the exergy loss associated with the air leaving the system from the outlet of the fourth stage reduces.

In summary, the exergy efficiency and work output corresponding to maximum thermal efficiency increase with increasing working temperature and stage efficiency. The maximum thermal efficiency increases with turbine efficiency and at a given stage efficiency it is almost constant at temperature investigated $(293 \mathrm{~K}-793 \mathrm{~K})$. The optimized expansion ratio of the fourth stage based on maximum thermal efficiency reaches the expansion ratio limit and is higher than those of the first three stages.

\subsection{Maximum Exergy Efficiency}

As shown in Equation (18), the exergy efficiency is defined as the ratio of the actual work output to the exergy entering the system in accordance with the second law of thermodynamics. Exergy loss of the system mainly consists of two components, one is the internal irreversible loss in radial turbines, and another is the loss in exergy associated with the air leaving the system from the outlet of the fourth stage radial turbine and the heating processes.

The expansion ratios of four stages corresponding to the maximum exergy efficiency are shown in Figure 8. For a given stage efficiency, the expansion ratios of the first three stages gradually decrease with increasing working temperature, however, that of the fourth stage increases monotonically before reaching the expansion ratio limit. The exergy leaving the system through exhaust air increases with increasing working temperature. As a result, the expansion ratio of the fourth stage needs to increase in order to minimize the exergy leaving the system. The expansion ratio of the fourth stage is influenced by the stage efficiency and it decreases as stage efficiency decreases. Higher expansion ratio of the fourth stage increases the internal irreversible loss when stage efficiency decreases, though it decreases the loss in exergy associated with the air leaving the system from the outlet of the fourth stage radial turbine, a compromise between them is decreasing the expansion ratio of the fourth stage. Higher stage efficiency will make the expansion ratio of the fourth stage reach the limit at lower working temperature. At low working temperature, heating processes will produce exergy loss, the expansion ratios of four stages must make the temperature at the outlet of each stage equal to minimize the exergy loss, so the expansion ratios of them are almost equal. 
Figure 8. Expansion ratio as a function of temperature.

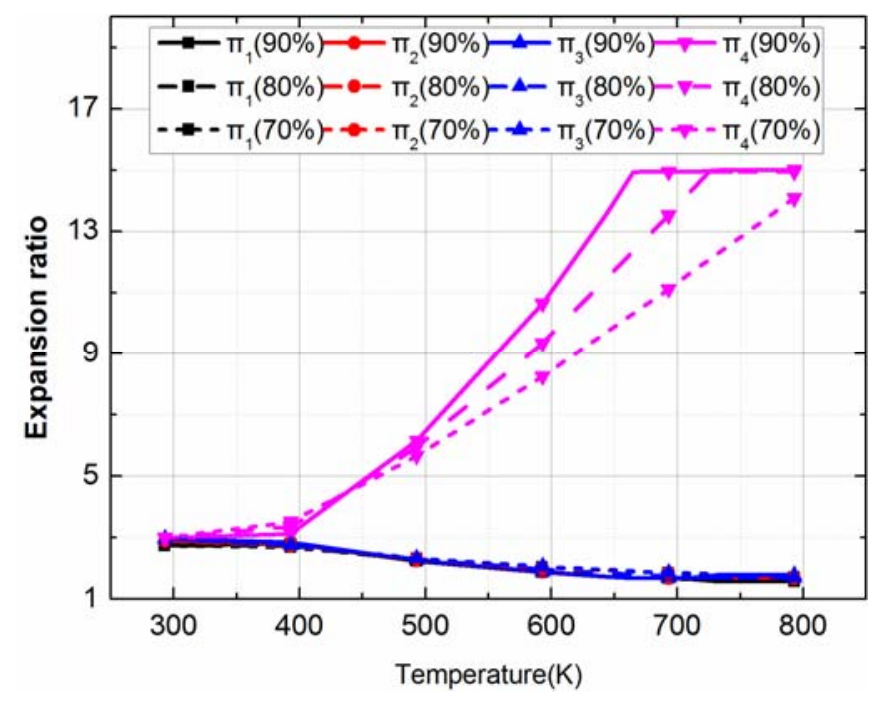

Figure 9 shows the characteristics of maximum exergy efficiency of the system as a function of working temperature and stage efficiency which consist of work output, thermal efficiency and exergy efficiency. It can be seen that, for a given stage efficiency, the maximum exergy efficiency increases sharply first and then the increase rate levels off with increasing the working temperature. After it reaches a maximum value, the maximum exergy efficiency slightly drops. In Figure 9, the maximum exergy efficiency occurs at $643 \mathrm{~K}$ and the value with $90 \%$ turbine efficiency is $91.9 \%$, whereas those with $80 \%$ and $70 \%$ turbine efficiency are $83.6 \%$ and $75.1 \%$ respectively. In Figure 9 , there exists an inflexion point for each given stage efficiency between $320 \mathrm{~K}$ and $350 \mathrm{~K}$. This is because if the working inlet temperature is low enough e.g. $320 \mathrm{~K}$, the air temperature after expansion could be lower than the ambient temperature. As a result, the heating process leads to the exergy loss, i.e. the exergy absorbed during the heating process is negative. The inflexion point represents the critical temperature that the exergy absorbed during the heating process changes from negative to positive. Meanwhile, the stage efficiency has significant influence on the exergy efficiency, if the stage efficiency increases by $10 \%$, the maximum exergy efficiency also increases by about $10 \%$.

In Figure 9, thermal efficiency corresponding to maximum exergy efficiency increases with increasing working temperature. This is because the expansion ratio of the fourth stage increases with increasing working temperature to make the energy leaving the system decrease. In comparation with the maximum thermal efficiency in Section 4.1, it can be found that at $293 \mathrm{~K}$ the difference between thermal efficiency corresponding to maximum exergy efficiency and maximum thermal efficiency is $7.2 \%$ and decreases with increasing working temperature, which is determined by the difference of expansion ratios of two cases.

One can see that the work output corresponding to maximum exergy efficiency increases monotonically with increasing working temperature and stage efficiency. If the working fluid is considered as ideal gas, the expansion ratios of four stages are equal to maximize the work output. Under maximum exergy efficiency the expansion ratios deviate from the optimum with increasing working temperature. But the enthalpy drop through expansion process increases with increasing temperature and its influence on work output is much stronger, as a result the work output increases. Compared with the work output under maximum thermal efficiency, the work output under maximum 
exergy efficiency is $10.5 \%$ higher than that corresponding to maximum thermal efficiency for $90 \%$ stage efficiency at $293 \mathrm{~K}$. the difference gradually decreases with increasing working, the variation of which results from the variation of expansion ratios.

Figure 9. Characteristics corresponding to maximum exergy efficiency.

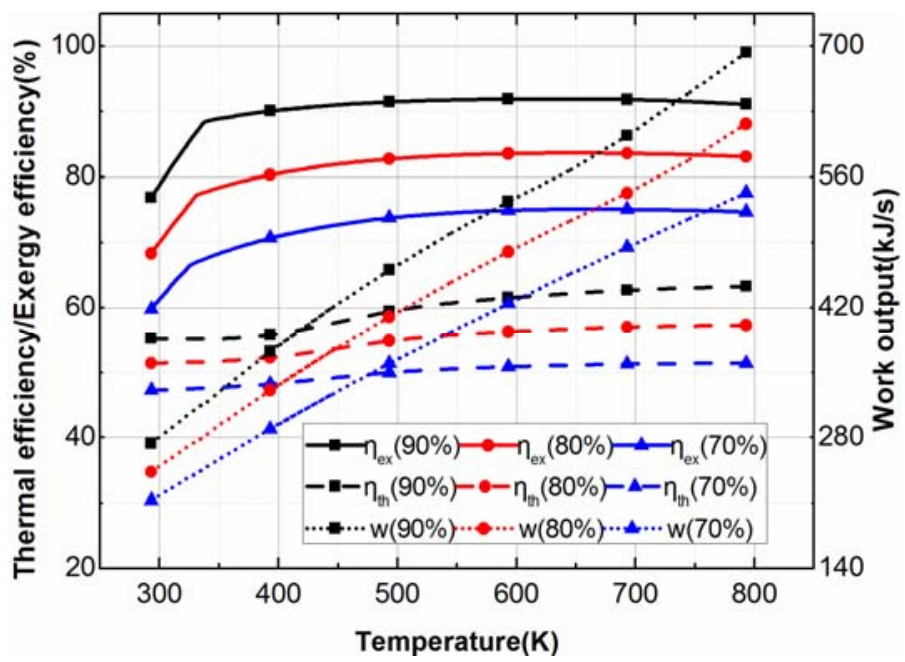

\subsection{Maximum Power Output}

The expansion ratios of the four stages corresponding to the maximum work output are plotted as a function of working temperature in Figure 10. All the expansion ratios of the four stages are in the range of 2.7 to 3.0. The expansion ratios converge for different stage efficiencies in each stage. This means that the stage efficiency has no influence on the expansion ratios of four stages radial turbine when the efficiency of each stage is equal. From the first stage to the fourth stage, the differences in expansion ratios gradually decrease with increasing working temperature. The variation behavior of expansion ratio in Figure 10 is resulted from variation of the air property at different temperatures and different pressures. If the working fluid is considered as ideal gas, the expansion ratios of four stages are equal and constant.

Figure 10. Expansion ratio as a function of temperature.

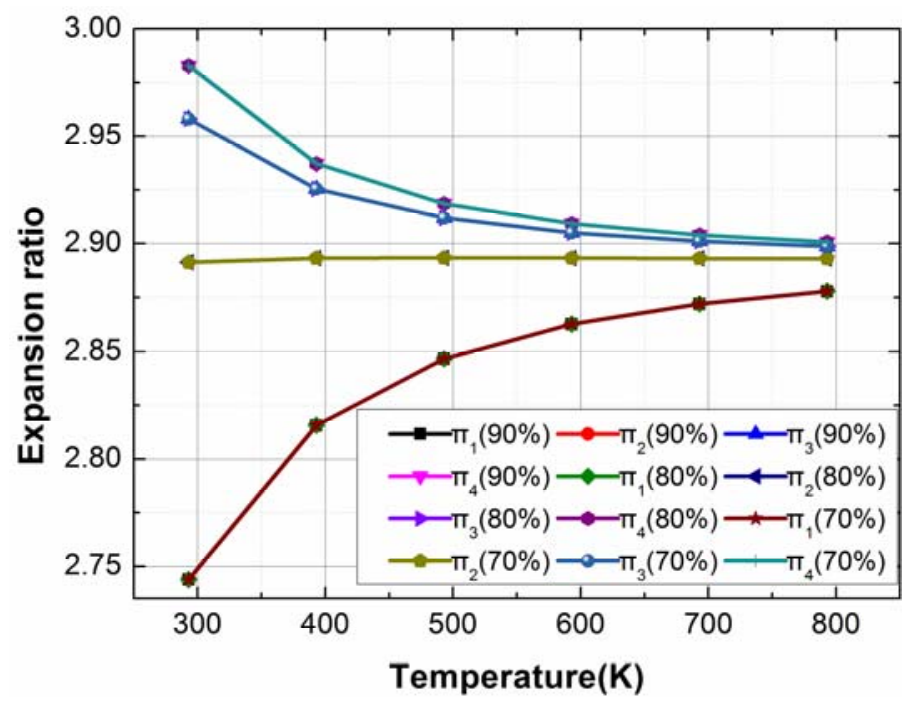


Figure 11 shows the characteristics under maximum work output. It can be seen that a high efficiency turbine and a higher temperature leads to greater work output. For example, at $293 \mathrm{~K}$, the maximum work output increases from $212.8 \mathrm{~kJ} / \mathrm{s}$ to $277.6 \mathrm{~kJ} / \mathrm{s}$ when the stage efficiency increases from $70 \%$ to $90 \%$. While at $793 \mathrm{~K}$ the maximum work output increases from $593.6 \mathrm{~kJ} / \mathrm{s}$ to $763.2 \mathrm{~kJ} / \mathrm{s}$. The reason is that a higher temperature will increase the ideal work output when other working conditions are same. According to Equation (5) the actual work output is the product of ideal work output and stage efficiency, so work output increases with increasing working temperature and stage efficiency. Compared with those under maximum thermal efficiency and maximum exergy efficiency, one can see that maximum work output is much more than that under maximum thermal efficiency at the working temperature investigated, and work output under maximum exergy efficiency and maximum work output match for lower temperature $(<500 \mathrm{~K})$.

The thermal efficiency under maximum work output is nearly constant at working temperature investigated which is about $7 \%$ lower than maximum thermal efficiency for $90 \%$ stage efficiency and the reason is the variation behavior of expansion ratios, which is analogous to that under maximum thermal efficiency.

Figure 11. Characteristics corresponding to maximum work output.

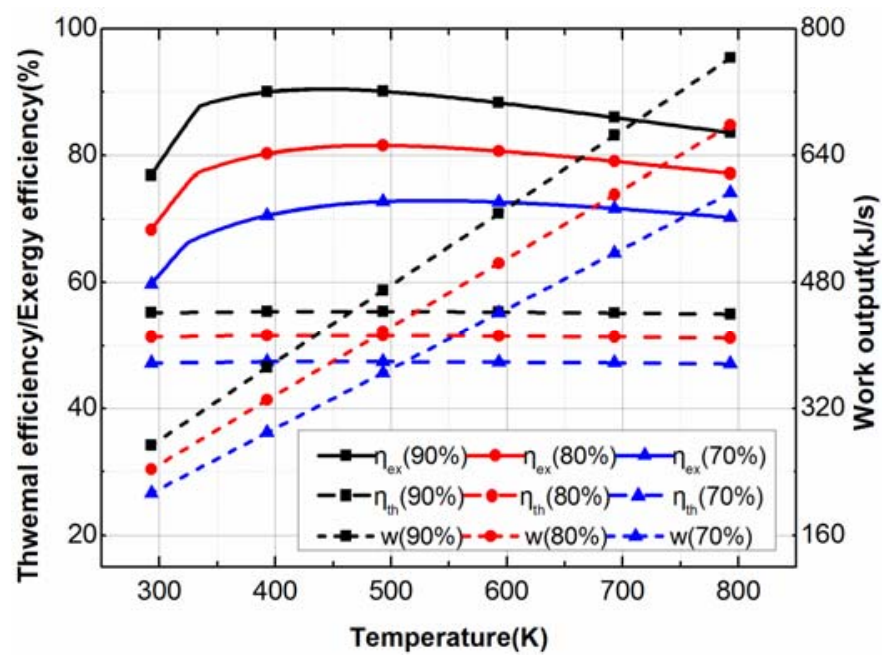

The exergy efficiency corresponding to the maximum work output is shown in Figure 11. For a given stage efficiency, the exergy efficiency corresponding to the maximum work output increases sharply to a maximum value and then drops slightly with increasing the working temperature. The difference of expansion ratios of four stages is little, the temperature in the outlet of each stage is mainly controlled by the working temperature. The exergy loss about them firstly decreases and then increase, so there exists a critical temperature where the exergy efficiency is maximum. Compared with maximum exergy efficiency in Section 4.2, it can be seen that the exergy efficiency corresponding to the maximum work output and maximum exergy efficiency are nearly identical at low working temperature $(300 \mathrm{~K}$ to $500 \mathrm{~K}$ ) and the maximum difference between them is about $8 \%$ at $793 \mathrm{~K}$, because the system absorbs more heat to produce maximum work output, the denominator in Equation (18) increases so that the exergy efficiency reduces. Meanwhile the exergy efficiency under maximum thermal efficiency is much less than maximum exergy efficiency because of higher expansion ratio of the fourth stage. 
From the above analysis, it is suggested that maximum work output be considered as the design criterion for multistage radial turbine with inter-heating in the range of working temperature investigated, maximum exergy efficiency also be considered as an optimization target at lower working temperatures, and maximum thermal efficiency be not a good design goal.

\section{Conclusions}

The characteristics and performance of a four-stage radial turbine system are analyzed thermodynamically. The following conclusions can be drawn from the analysis:

(1). It is found that the maximum thermal efficiency, maximum exergy efficiency and maximum work output of the four stage radial turbine with inter-heating are $62.6 \%, 91.9 \%$, and $763.2 \mathrm{~kJ} / \mathrm{s}$, respectively. However, the thermal efficiency, exergy efficiency and work output are not equivalent.

(2). At low working temperatures (below $500 \mathrm{~K}$ ) both maximum exergy efficiency and maximum work output can be used as the design objective of the multi-stage radial turbine, however, only maximum work output can be used as the design objective of the turbine over the whole working temperature range in this work.

(3). The maximum thermal efficiency can't be used as the design objective for the turbine.

\section{Acknowledgments}

The authors would like to thank the following organizations for financial support of the work: Beijing Natural Science Foundation under grant No.3122033, National Natural Science Foundation of China under grant No.50906079, and the National 973 Research Program of China under grant No. 2012CB720400.

\section{References}

1. Rodgers, C. The characteristics of radial turbines for small gas turbines. In Proceedings of ASME Turbo Expo 2003 Power for Land, Sea, and Air, Atlanta, GA, USA, 16-19 June 2003; GT2003-38026.

2. Balje, O.E. Turbomachines, 1st ed.; John Wiley \& Sons: New York, NY, USA, 1981; pp. 297-316.

3. Whitfield, A. The preliminary design of radial inflow turbines. J. Turbomach. 1990, 112, 50-57.

4. Dambach, R.; Hodson, H.P.; Huntsman, I. An experimental study of tip clearance flow in a radial inflow turbine. J. Turbomach. 1999, 121, 644-670.

5. Bruno, J.C.; Ortega-lopez, V.; Coronas, A. Integration of absorption cooling sysytems into micro gas turbine trigeneration systems using biogas: Case study of sewage treatment plant. Appl. Energy 2009, 86, 837-847.

6. He, P.; Sun, Z.; Guo, B.; Tan, C. Numerical simulation of the backface clearance flow in a deeply scalloped radial turbine. J. Eng. Thermophys. 2011, 32, 1303-1306.

7. Hung, T.C.; Shai, T.Y.; Wang, S.K. A review of organic Rankine cycles (ORCs) for the recovery of low-grade waste heat. Energy 1997, 22, 661-667.

8. Chow, T.T. A review on photovoltaic/thermal hybrid solar technology. Appl. Energy 2010, 87, 365-379. 
9. Thirugnanasambandam, M.; Lniyan, S.; Goic, R. A review of solar thermal technologies. Renew. Sust. Energy Rew. 2010, 14, 312-322.

10. Kim, Y.M.; Favrat, D. Energy and exergy analysis of a micro-compressed air energy storage and air cycle heating and cooling system. Energy 2010, 35, 213-220.

11. Rodgers, C.; Geiser, R. Performance of a high-efficiency radial/axial turbine. J. Turbomach. 1987, $109,151-154$.

12. Chen, Y.; Xu, H.; Tao, G.; Wang, X.; Liu, H.; Jia, G. Research and progress of the compressed air vehicle. Chin. J. Mech. Eng. 2002, 38, 7-11.

13. Shen, Y.T.; Hwang, Y.T. Design and implementation of an air-powered motorcycles. Appl. Energy 2009, 86, 1105-1110.

14. Chen, H.; Ding, Y.; Li, Y.; Zhang, X.; Tan, C. Air fuelled zero emission road transportation: A comparative study. Appl. Energy 2011, 88, 337-342.

15. Chen, H.; Cong, T.N.; Yang, W.; Tan, C.; Li, Y.; Ding, Y. Progress in electrical energy storage system: A critical review. Prog. Nat. Sci. 2009, 19, 291-312.

16. Xu, Y.; Chen, H.; Liu, J.; Tan, C. Performance analysis on an integrated system of compressed air energy and electricity production with wind-solar complementary method. Proc. CSEE 2012, $32,88-95$.

17. Chen, H.; Zhang, X.; Yan, X.; Meng, A.; Tan, C. A system of multi-stage radial turbine. Chinese Patent 201120130044.8, accessed on 28 April 2011.

18. Chen, H.; Zhang, X.; Yan, X.; Meng, A.; Tan, C. A system of back-to-back multi-stage radial turbine. Chinese Patent 201220059417.1, accessed on 21 February 2012.

19. Zhu, Z.; Yao, Y.; Yang, J.; Xiong, L.; Hou, Y.; Chen, C. The research development of cryogenic helium turboexpander. Chin. Low Temp. Speci. Gases 2003, 21, 1-6.

20. Chen, H.; Baines, N.C. The aerodynamic loading of radial and mixed-flow turbines. Int. J. Mech. Sci. 1994, 36, 63-79.

21. Korakianitis, T.; Wilson, D. Models for predicting the performance of Brayton-cycle engines. J. Eng. Gas. Turb. Power 1994, 116, 381-388.

22. Chen, H.; Baines, N.C. Analytical optimization design of radial and mixed flow turbine. Proc. Instn. Mech. Engrs. Part. A: J. Power Energy 1992, 206, 177-187.

(C) 2013 by the authors; licensee MDPI, Basel, Switzerland. This article is an open access article distributed under the terms and conditions of the Creative Commons Attribution license (http://creativecommons.org/licenses/by/3.0/). 